\title{
Evaluation Of the Effect of a Self-Developed Exercise Program in An Outdoor Gym on The Physical Fitness of People Over 60 Years of Age
}

\author{
Agnieszka Kowalska ${ }^{1}$, Joanna Czesak ${ }^{\mathbf{1}}$ \\ ${ }^{1}$ Department of Rehabilitation in Rheumatology and Geriatrics, Institute of Clinical Rehabilitation, \\ University School of Physical Education in Krakow, Krakow, Poland \\ Correspondence to: Agnieszka Kowalska, email: agakowalska1996@interia.pl \\ DOI: https://doi.org/10.5114/phr.2021.109030
}

Received: 14.02.2021 Reviewed: 06.03.2021 Accepted: 06.03.2021

\section{Abstract}

Aims: To evaluate the effect of a 4-week training program in an outdoor gym on the physical fitness of individuals aged 60-74 years measured by the Fullerton test.

Material and methods: A total of 31 subjects were eligible, of whom 26 subjects (18 women and 8 men) completed the study (mean age of $66.8 \pm 4$ years). Before and after the 4 -week training period in an outdoor gym, the participants subjectively rated their physical fitness, muscular strength, flexibility, endurance, and mood using a self-designed rating scale. A Fullerton test was also administered before and after the training program. Training in the outdoor gym was performed 3 times per week in 45-minute sessions for 4 weeks.

Results: It was observed that the 4-week training program in an outdoor gym significantly improved the participants' subjective ratings of their own physical fitness, muscular strength, flexibility, endurance, and mood. There was a statistically significant improvement in all parameters assessed by the Fullerton test. There was also a significant decrease in body mass index (BMI) after the 4-week training program.

Conclusions: Training in an outdoor gym has a remarkable effect on fitness components, as shown by the Fullerton test, BMI reduction, and self-assessment of health and well-being.
Key words

fitness,

Fullerton test, older adults, physical activity, outdoor gym 


\section{Introduction}

By the end of 2018, people aged 60 and older accounted for nearly $25 \%$ of the total population. Moreover, people aged 60-64 were the largest group in the elderly subpopulation [1]. Aging is a natural and inevitable process characterized by different speeds and intensities of changes occurring with age. The level of fitness and physical performance decreases with age, mainly due to involutionary changes [2]. As a result of these processes, physical fitness deteriorates, which is the primary indicator of the quality of life of older adults [3]. However, this involutionary process can be slowed down through regular exercise and training [2].

The World Health Organization (WHO) recommends for older adults at least 150 minutes of respiratory-enhancing physical activity per week with moderate intensity or 75 minutes of vigorous exercise. In addition, exercises that strengthen the major muscle groups at least twice a week are also advisable [4].

The physical fitness of older adults should be assessed using a test designed for them and according to specific standards. To this end, Rikli and Jones [5] developed the Fullerton test to provide a comprehensive physical fitness assessment for people over 60 years of age. The Fullerton test assesses lower and upper limb muscle strength, upper and lower body flexibility, dynamic agility and balance, and aerobic capacity.

\section{Aims}

This study aimed to assess the effect of a 4-week training program in an outdoor gym on the physical fitness of subjects aged 60-74 years measured using the Fullerton test.

\section{Materials and methods}

The study material consisted of 31 subjects, of whom 26 (18 women and 8 men) completed the study. It should be noted that 4 subjects dropped out of the study due to health deterioration and 1 due to personal issues. The participants in the study had no comorbidities, went to gymnastics classes for seniors at the RONDO Club in Inowrocław (Poland), and were members of the University of the Third Age in Inowrocław (Poland). The subjects received information about the study and signed their consent to participate.

The inclusion criteria were an age between 60 and 74 years and voluntary consent to participate in the study. In addition, a lack of consent to participate in the study and diseases that are contraindications to exercise in an outdoor gym were considered exclusion criteria. Table 1 shows the characteristics of the study group.

Before and after the 4-week training period, the participants completed a questionnaire for collecting demographic data. In addition, the participants subjectively assessed their physical fitness, muscular strength, endurance, flexibility, and general well-being, for which the authors de-

Table 1. Characteristics of the study group.

\begin{tabular}{|l|l|l|l|l|}
\hline Variable & $\overline{\mathbf{x}}$ & SD & Min & Max \\
\hline Age (years) & 66.8 & 4 & 61 & 74 \\
\hline Body height $(\mathrm{cm})$ & 167.3 & 7.3 & 157 & 184 \\
\hline Body weight $(\mathrm{kg})$ & 73.6 & 11.4 & 53 & 98 \\
\hline \multicolumn{4}{|c|}{ Abbreviations: $\overline{\mathrm{x}}$ - mean, SD - standard deviation, Min - minimum, Max - maximum. } \\
\hline
\end{tabular}


signed a 10-item scale, each answer ranging from 1 (very poorly) to 10 (very well). The questionnaire also included a question about physical activity during leisure time and its forms.

Additionally, the following Fullerton test consisting of six tasks was administered before and after the training program:

- Standing up from a chair for 30 seconds to assess lower limb muscle strength;

- Flexing forearms for 30 seconds to assess upper limb muscle strength;

- Sitting on a chair and reaching to assess lower limb flexibility;

- Scratching one's back to assess upper limb flexibility;

- Standing up from a chair and walking to assess agility and dynamic balance;

- Walking for 6 minutes to assesses aerobic capacity and the distance a person can walk in 6 minutes [5].

The subjects were randomly divided into five subgroups. The 4-week training was conducted between June 15 and August 9, 2019 for three of the subgroups and between August 19 and September 13, 2019 for the remaining two subgroups. The training was performed for 4 weeks, 3 times a week in 45-minute sessions in an outdoor gym in Solankowy Park in Inowrocław (Poland). Each training session included a 10-minute warm-up, a 30-minute main part, and a 5-minute end part. In the main part, the participants exercised on six devices (i.e., rider, surfer, overhead hoist, orbiter, jogger, and foot press) on the principle of station circuit (five times on each device). In order to progress the training, in week 1 , the exercise time was 20 seconds and the break time with device change was 40 seconds, whereas in weeks 2,3 , and 4 , the exercise and break time were 30 seconds each. In the end part of the training, stretching and breathing exercises were performed.

Statistical analysis was performed using Statistica 13 and MS Excel. The Shapiro-Wilk test $(\mathrm{p}<0.05)$ was used to assess the normality of the distribution. For study samples with normal distribution, we employed the parametric Student's t-test $(\mathrm{p}<$ 0.05 ), and when the study sample had a distribution different from normal, the non-parametric Wilcoxon test $(p<0.05)$ was utilized.

\section{Results}

After the 4-week training program, a significantly higher number of repetitions was observed in the tests of standing up from a chair for 30 seconds and flexion of the right and left forearms for 30 seconds. There was also a significant difference in the distance in the sit-to-stand and reach tests for the right and left lower limbs and in the back-scratch test for both the right and left upper limb. Another improvement was the significant decrease in the time required to perform the stand-up and walk test and the increase in the distance covered in the 6 -minute walk test. The training program was also shown to significantly reduce the body mass index (BMI) of the participants (Table 2).

Table 2. Analysis of differences in Fullerton test and body mass index by Student's t-test before and after 4-week training in the study group.

\begin{tabular}{|l|l|l|l|l|l|l|}
\hline Variable & & $\overline{\mathbf{x}}$ & Difference & Df & t Stat & $\mathbf{p}$-Value \\
\hline $\begin{array}{l}\text { Lower limb muscle } \\
\text { strength (repetitions) }\end{array}$ & Before & 16.35 & -2.42308 & 25 & -6.29371 & $0.000001^{*}$ \\
\cline { 2 - 7 } & After & 18.77 & & & & \\
\hline $\begin{array}{l}\text { Right upper limb muscle } \\
\text { strength (repetitions) }\end{array}$ & Before & 18.19 & -3.46154 & 25 & -7.78645 & $0.000000^{*}$ \\
\cline { 2 - 8 } & After & 21.65 & & & & \\
\hline
\end{tabular}




\begin{tabular}{|c|c|c|c|c|c|c|}
\hline \multirow{2}{*}{$\begin{array}{l}\text { Left upper limb muscle } \\
\text { strength (repetitions) }\end{array}$} & Before & 18.42 & -3.0000 & 25 & -5.93641 & $0.000003^{*}$ \\
\hline & After & 21.42 & & & & \\
\hline \multirow{2}{*}{$\begin{array}{l}\text { Right upper limb muscle } \\
\text { strength (repetitions) }\end{array}$} & Before & -5.62 & -6.26923 & 25 & -4.71098 & $0.000070^{*}$ \\
\hline & After & 0.65 & & & & \\
\hline \multirow{2}{*}{$\begin{array}{l}\text { Lower limb muscle } \\
\text { strength (repetitions) }\end{array}$} & Before & -5.92 & -6.26923 & 25 & -4.62345 & $0.000090^{*}$ \\
\hline & After & 0.35 & & & & \\
\hline \multirow{2}{*}{$\begin{array}{l}\text { Right upper limb muscle } \\
\text { strength (repetitions) }\end{array}$} & Before & -6.81 & -3.42308 & 25 & -4.3616 & $0.0001949 *$ \\
\hline & After & -3.38 & & & & \\
\hline \multirow{2}{*}{$\begin{array}{l}\text { Lower limb muscle } \\
\text { strength (repetitions) }\end{array}$} & Before & -9.12 & -3.53846 & 25 & -4.00076 & $0.000490^{*}$ \\
\hline & After & -5.58 & & & & \\
\hline \multirow{2}{*}{$\begin{array}{l}\text { Right upper limb muscle } \\
\text { strength (repetitions) }\end{array}$} & Before & 5.37 & 0.196538 & 25 & 2.594272 & $0.015000 *$ \\
\hline & After & 5.17 & & & & \\
\hline \multirow{2}{*}{$\begin{array}{l}\text { Lower limb muscle } \\
\text { strength (repetitions) }\end{array}$} & Before & 574.65 & -42.4231 & 25 & -7.49755 & $0.000000 *$ \\
\hline & After & 617.08 & & & & \\
\hline \multirow{2}{*}{$\begin{array}{l}\text { Right upper limb muscle } \\
\text { strength (repetitions) }\end{array}$} & Before & 26.28 & 0.33912 & 25 & 2.558 & $0.0169 *$ \\
\hline & After & 25.94 & & & & \\
\hline
\end{tabular}

There was a significant improvement in the participants' subjective assessment of their own physical fitness, muscular strength, flexibility, endurance, and well-being after the training program (Table 3).

Table 3. Analysis of differences in subjective assessment of physical fitness, muscle strength, flexibility, endurance and well-being using the Wilcoxon test before and after 4-week training in the study group.

\begin{tabular}{|l|l|l|l|l|}
\hline Variable & N & T & Z & p-Value \\
\hline Physical fitness before \& after & 19 & 15 & 3.219375 & $0.00121^{*}$ \\
\hline Muscle strength before \& after & 21 & 13 & 3.562659 & $0.000367^{*}$ \\
\hline Flexibility before \& after & 23 & 57 & 2.463611 & $0.013755^{*}$ \\
\hline Endurance before \& after & 19 & 15 & 3.219375 & $0.001285^{*}$ \\
\hline Well-being before \& after & 16 & 3 & 3.361070 & $0.000777^{*}$ \\
\hline \multicolumn{2}{|r|}{ Abbreviations: N - number of participants; * - significance level for $\mathrm{p}<0,05$} \\
\hline
\end{tabular}




\section{Discussion}

Based on the obtained results, it can be concluded that the 4-week training program at an outdoor gym allowed for a significant improvement in the self-assessment of health and well-being of the respondents. The obtained results are even more remarkable, as, according to a study by Ignasiak et al. [6], only $13 \%$ of the surveyed women aged over 55 assessed their physical fitness as good, $50 \%$ as average, and $37 \%$ as bad. Furthermore, Zanuso et al. [7] demonstrated that after physical activity, the feeling of positive emotions increases and the feeling of negative emotions decreases, which may improve general well-being.

In our study, the training program used a rider, surfer, overhead hoist, orbiter, jogger, and foot press as the training equipment in the outdoor gym. On the other hand, in a 6-week supervised outdoor gym training program presented by Kim et al. [8], the subjects were divided into control groups performing resistance exercises and resistance-endurance exercises. For resistance training, an overhead lift, rider, and leg extender were used, while for aerobic training, a jogger was utilized. On the other hand, Johnson et al. [9] used four stationary devices: rowing machine, hand press, overhead hoist and squat, and two modules for performing lunges and push-ups. In that training program, before the first workout, the participants were instructed on how to perform the exercises on the equipment properly, after which they conducted the training sessions independently. The subjects in the study were between 33 and 50 years old.

Our study suggests that a 4-week training program in an outdoor gym leads to significant improvements in all components of the Fullerton test. Kim et al. [8] had their subjects stand up from a chair, perform forearm flexion, stand up and walk, walk for 2 minutes in place, and walk for 6 minutes to evaluate the effects of a 6 -week training program. After both resistance and resistance-endurance exercises, the researchers observed statistically significant improvements in all the studied components of the Fullerton test. Moreover, Hand et al. [10] proved that a 12week endurance training program or endurance training combined with strength training allows for statistically significant $(p<0.003)$ improvements in the physical fitness parameters evaluated with the Fullerton test, except for upper limb flexibility, dynamic agility, and balance. Konstantinidis et al. [11] proved that 8-week training protocol on the FitForAll (FFA) platform that uses virtual reality and console games to perform aerobic, resistance, flexibility, and balance exercises enables statistically significant improvements in Fullerton test scores. Cristi et al. [12] showed that whole-body vibration training allows for statistically significant increases in upper and lower limb muscle strength, agility, and dynamic balance. The 8-week Nordic Walking training protocol proposed by Hagner-Derengowska et al. [13] also enables statistically significant improvement of the results obtained in the Fullerton test. Curi et al. [14] suggested that a 16-week Pilates training program allows for a statistically significant improvement in all components of the Fullerton test. Douka et al. [15] presented a positive effect of a 32-week dance program on physical fitness. What is more, the 24-week dance program used by Zilidou et al. [16] resulted in statistically significant improvements in lower limb muscle strength and flexibility, agility, and dynamic balance. Although these programs differ in type, intensity, and duration, the obtained results have a positive impact on physical fitness but not always on all components of the Fullerton test.

In our study, we noted a positive effect of regular physical activity on the reduction of the BMI. The 12-week aerobic training program proposed by Hand et al. [8] reduced BMI values. However, a 9 -week training program on a vibrating platform [10] and even a 6-month Pilates or aqua fitness training program [17] did not change BMI values significantly. Regular physical activity allows the maintenance of an appropriate level of physical fitness, which is necessary to ensure the best possible quality of life for older adults, regardless of the ongoing involutionary changes [2]. 


\section{Conclusions}

Our 4-week outdoor gym training program had a significant effect on physical fitness components assessed by the Fullerton test in 26 subjects aged $60-74$ years. In addition, the training protocol si- gnificantly decreased the participants' BMI values and significantly improved their self-assessed health and well-being.

\section{References}

1. Statistics Poland. The situation of older people in Poland in 2018. Warszawa, Białystok 2020. https://stat.gov.pl/ en/topics/older-people/older-people/the-situation-of-older-people-in-poland-in-2018,1,1.html (27.02.2021).

2. Gębka D, Kędziora-Kornatowska K. Benefits of health training in elderly people. Probl Hig Epidemiol. 2012; 93 (2): 256-259.

3. Urgacz K, Cholewa J, Uher I, Sahin B, Cholewa J. Senior Fitness Test in assessing the effectiveness of physical rehabilitation in the context of Parkinson's disease patients quality of life. Phys Activ Rev. 2018; 6: 110-116.

4. World Health Organization. Health Topics. Fact sheets. Physical activity. WHO 2020. https://www.who. int/news-room/fact-sheets/detail/physical-activity (01.02.2021).

5. Rikli RE, Jones CJ. Measuring functional fitness of older adults. J Active Aging. 2002; 1 (1): 24-30.

6. Ignasiak Z, Nowak A, Domaradzki J, Falkenberg J. Wpływ 8-tygodniowego treningu Nordic Walking na wybrane parametry somatyczne i zmiany zakresów ruchów w stawach starszych kobiet. Antropomotoryka 2013; 23 (63): 39-46.

7. Zanuso S, Sieverdes JC, Smith N, Carraro A, Bergamin $M$. The effect of a strength training program on affect, mood, anxiety, and strength performance in older individuals. Int. J Sport Psychol. 2012; 43 (1): 55-66.

8. Kim DI, Lee DH, Hong S, Jo SW, Won YS, Jeon JY. Six weeks of combined aerobic and resistance exercise using outdoor exercise machines improves fitness, insulin resistance, and chemerin in the Korean elderly: A pilot randomized controlled trial. Arch Gerontol Geriatr. 2018; 75: 59-64.

9. Johnson U, Ivarsson A, Parker J, Andersen MB, Svetoft I. Connection in the fresh air: A study on the benefits of participation in an electronic tracking outdoor gym exercise programme. MJSSM 2019; 8 (1): 61-67.
10. Hand B, Cavanaugh S, Forbes W, Govern J, Cress ME. Changes in Health-Related Quality of Life and Functional Fitness with Exercise Training in Older Adults Who Attend Senior Centers. Act Adapt Aging. 2012; 36 (1): 29-54.

11. Konstantinidis EI, Billis AS, Mouzakidis CA, Zilidou VI, Antoniou PE, Bamidis PD. Design, implementation and wide pilot deployment of FitForAll: an easy to use exergaming platform improving physical fitness and life quality of senior citizens. IEEE J Biomed Health Inform. 2016; 20 (1): $189-200$.

12. Cristi C, Collado PS, Márquez S, Garatachea N, Cuevas MJ. Whole-body vibration training increases physical fitness measures without alteration of inflammatory markers in older adults. Eur J Sport Sci. 2013; 14 (6): 611-619.

13. Hagner-Derengowska M, Kałużny K, Budzyński J. The effect of nordic walking trainig on the parameters of gait and physical fitness in postmenopausal women. Polish J Sport Med. 2015; 4 (4): 179-186.

14. Curi VS, Haas AN, Alves-Vilaça J, Fernandes HM. Effects of 16-weeks of Pilates on functional autonomy and life satisfaction among elderly women. J Bodyw Mov Ther. 2018; 22 (2): 424-429.

15. Douka S, Zilidou VI, Lilou O, Manou V. Traditional Dance Improves the Physical Fitness and Well-Being of the Elderly. Front Aging Neurosci. 2019; 11: 1-9.

16. Zilidou VI, Frantzidis CA, Romanopoulou ED, Paraskevopoulos E, Douka S, Bamadis PD. Functional Re-organization of Cortical Networks of Senior Citizens After a 24-Week Traditional Dance Program. Front Aging Neurosci. 2018; 10: 1-14.

17. Kovách MV, Plachy JK, Bognár J, Balogh ZO, Barthalos I. Effects of Pilates and aqua fitness training on older adults' physical functioning and quality of life. Biomed Hum Kinet. 2013; 5 (1): 22-27. 